\title{
Exchange Market Pressure and the Credibility of Macau's Currency Board
}

\author{
Jorge Braga de Macedo, José Braz, Luís Brites Pereira, Luís C. Nunes*
}

July 13, 2004

\begin{abstract}
In this study, we assess the credibility of the currency board arrangement (CBA) of the Macau Special Administrative Region by studying the relationship between exchange market pressure (EMP) and the anchors of a rule-based CBA, namely, interest rate arbitrage, exchange rate arbitrage and economic discipline. A pure CBA signals its credibility by allowing the first two anchors to function automatically and by pursuing sound fiscal policies. The analysis' results suggest that Macau's CBA has been characterised by a state of low volatility since late 1992, with the brief exception of the East Asian financial crisis period. The paper's main finding is that fiscal fundamentals seem to have a more pronounced role in reducing EMP's variability during periods of low volatility whilst interest rate arbitrage is more important in periods of high volatility. We conclude that Macau's CBA is credible at present as reflected in the low frequency of observed EMP, in the narrowing of Macau's interest rate differential vis-à-vis U.S. interest rates and in Macau's substantial fiscal reserves.
\end{abstract}

Keywords: Currency Board Arrangement, Exchange Market Pressure, Regime-Switching.

JEL-Code: C22, F31, F33.

${ }^{*}$ Corresponding author: Luís Brites Pereira. Email address: lpereira@fe.unl.pt. Postal address: Faculdade de Economia, Universidade Nova de Lisboa, Campus de Campolide. P-1099-032 Lisboa, Portugal. Phone: +351-21 380 1600. Fax: +351-21 3886073 . We thank the Monetary Authority of Macao (AMCM) for kindly providing us with financial support. An earlier version of this study was presented at the AMCM on March 2, 2004. All comments received are gratefully acknowledged. The usual disclaimer applies. 


\section{Introduction}

Policymakers perception of currency board arrangements (CBAs) have changed since the advent of the global financial turmoil that began in East Asia in 1997. Although CBAs imply a loss of monetary and exchange rate independence, they allow for greater financial integration and exchange rate stability. As a result, currency boards are increasingly promoted as a means of enforcing financial discipline and of stabilising economies in the wake of financial instability. Examples of well-established CBAs include Djibouti (1949), Brunei Darussalam (1967) and Hong Kong (1983). The adoption of CBAs in Argentina, Estonia, Lithuania and Bulgaria during the early 1990's together with more recent proposals to extend these to Russia and Indonesia has further contributed to a renewed interest in this particular form of a fixed exchange rate regime.

The study of CBAs is, however, largely neglected in mainstream economics even though they have been adopted in a variety of institutional forms since their creation in Mauritius in 1849. The reasons for this oversight are twofold: first, the economies that implemented CBAs tend to be small and generally lacking in global influence; second, the lack of systematic and detailed data hinders serious empirical research on CBAs. The present research hopes to improve upon this state of affairs by studying the CBA of the Chinese Special Administrative Region (SAR) of Macau.

Macau's prevailing CBA has not been the subject of systematic research even though its sound economic performance has been widely acknowledged in international financial markets. For example, Moody's Investor Service upgraded Macau's credit rating twice in 2003, once in February from Baa1 to A3, and again in October from A3 to A1. In addition, Macau's CBA is characterised by a double-peg arrangement of its currency, the Pataca (MOP), that is unique in the annals of international exchange rate arrangements (Scott, 1997). Although the Pataca's formal link is to the Hong Kong dollar (HKD), it has a de facto link to the U.S. dollar (USD), as the HKD is itself pegged to the USD.

The main objective of our study is to assess the credibility of Macau's rulebased CBA, which can be inferred by studying the relationship between exchange market pressure (EMP) and the three anchors used to fix the exchange rate, namely interest rate arbitrage, exchange rate arbitrage and economic 
discipline. A pure CBA allows the first two anchors to function automatically and by pursues sound fiscal policies. As a result, the CBA's credibility is reflected in the narrowing of interest rate differentials vis-à-vis the anchor currency, exchange rate and/or foreign reserves stability and either zero or low government debt.

Following the approach adopted in Braga de Macedo, Nunes and Brites Pereira (2003), we study the stochastic properties of EMP by employing a Markov regime-switching framework with an Exponential Generalized Autoregressive Conditional Heteroscedasticity (MSGARCH) model. Specifically, we assess how the dependent variable of EMP responds to lagged changes in explanatory variables that capture the effect of the CBA's three anchors. The regime-switching framework is chosen as it is best suited to capture the stylised features of EMP dynamics, such as volatility clustering, asymmetric response of volatility to different types of shocks, non-normality, time-varying transition probabilities and possible differences in the distributions across regimes.

Our results suggest that Macau's CBA is stable and has been characterised by a state of low volatility since late 1992, with the brief exception of the East Asian financial crisis period (1997-98). The paper's main finding is that fiscal fundamentals have a more pronounced role in reducing EMP variability during "normal" times when volatility is low whilst interest rate arbitrage is more important in crisis periods when volatility is high. We also find evidence in favour of the exchange rate arbitrage mechanism during periods of low-volatility but it appears that this mechanism is not as important as either interest rate arbitrage or fiscal discipline. Overall, we conclude that Macau's CBA is credible at present. In practice, this credibility is reflected in the low frequency of observed EMP, in the narrowing of Macau's interest rate differential vis-à-vis U.S. interest rates and in its substantial fiscal reserves.

The remainder of the paper is organised as follows: section 2 discusses the operation of CBAs and briefly reviews Macau's historical CBA experience. Section 3 discusses the empirical methodology employed and the estimation results. Section 4 concludes. 


\section{Currency Board Arrangements}

\subsection{Theoretical Overview}

A CBA is a monetary regime based on an explicit legislative commitment to exchanging domestic currency for a specified foreign currency (reserve currency) at a fixed exchange rate, combined with restrictions on the issuing authority the currency board, to ensure the fulfillment of its legal obligation (Baliño and Enoch, 1997). ${ }^{1}$ A typical currency board can therefore only issue notes and coins when these are fully backed by foreign exchange reserves at a fixed exchange rate against a designated foreign currency. In other words, a CBA represents an unequivocal commitment to supply or redeem, without limit, the monetary liabilities issued by the currency board at that fixed rate. The exchange rate can be fixed in one of two ways: either by using foreign exchange controls and/or government interventions in the market, or second, by directly harnessing self-interested market forces. The latter approach underlies the classical CBA theory, as it relies on three specific anchors to bind the exchange rate, namely, interest rate arbitrage (specie flow), exchange rate arbitrage economic and discipline, which mutually reinforce one another.

In theory, the fact that new cash issues are only possible with a balance of payments surplus ensures economic discipline in monetary and fiscal policy. As such, it is not possible for the currency board to extend credit to the government or to the banking system, which implies a loss of monetary sovereignty. The consequence for fiscal policy is also clear: the absence of printing press finance implies the acceptance of a hard budget constraint and, by extension, public debt levels must be kept within limits of serviceability. Sound fiscal policies improve the credibility of the chosen peg because the political cost of policy failure is higher with an explicit commitment to maintain the CBA. In sum, the strong commitment to the external currency stability limits the scope of discretionary policies and reduces the probability of irresponsible behaviour by political decision makers. Economic discipline is thus able to generate confidence and contributes to exchange rate stability.

The anchor of economic discipline alone is insufficient to fix the exchange rate, however. Two automatic stabilizers, namely interest rate and exchange

\footnotetext{
${ }^{1}$ For a discussion regarding the operation of some existing CBAs refer to Bennett (1993), Baliño and Enoch (1997), Tsang (1999), Hong Kong Monetary Authority (2000), Pao (2003) and Gerlach (2003).
} 
rate arbitrage, are needed to provide additional anchorage. The interest rate arbitrage mechanism works as follows: an outflow of capital, possibly due to doubts about the exchange rate and the economy's weakness, causes the money supply to contract and domestic interest rates to rise. In turn, the higher interest rates induce an immediate counter-flow of funds that automatically stabilises the exchange rate without government intervention (Hanke, Jonung and Schuler, 1993). This adjustment is possible because interest rates are purely market-determined in a CBA, given the link to interest rates in the country to whose currency the domestic currency is anchored. The adjustment process is further predicated on the absence of exchange rate risk or persistent economic uncertainty. Should the exchange rate be seen to be unstable, a substantial interest rate premium might be needed in order to induce the desired capital counter-flow. In turn, the higher interest rates might be regarded as a sign of weakness, which leads to a vicious circle. Under these circumstances, the mechanism of interest rate arbitrage alone is incapable of fixing the exchange rate.

Hence, the need for a second adjustment mechanism that directly binds the exchange rate in a CBA, namely exchange rate arbitrage (alternatively known as currency or cash arbitrage). Cash arbitrage can be carried out because the currency board has sufficient foreign reserves to cover all of the cash in circulation. Should the market exchange rate weaken below the official rate, agents can first convert their bank deposits into cash in order to exchange it into foreign currency at the stronger official rate, and then sell the foreign currency thereby obtaining an arbitrage profit. Exchange rate arbitrage appeals to the self-interest of market participants when the market exchange rate deviates form the official parity, not unlike the arbitrage process under the gold standard where people shipped gold bullion between countries (Officer, 1993). As a result, the selling pressure on the foreign currency will bring the market exchange rate back to the level of its official counterpart .

In practice, existing CBAs have different institutional, policy and macroeconomic drawbacks that prevent the unhindered operation of the automatic stabilisers. For example, monetary authorities often opt for proactive measures in their defence of the established exchange rate, such as discretionary foreign exchange market intervention and/or resort to interest rate changes. In doing so, the degree of "automaticity" of the CBA adjustment process is 
reduced thereby compromising the assured benefits of the CBA's hard peg. In contrast, a pure CBA will signal its credibility by allowing the interest rate and exchange rate arbitrage mechanisms to function effectively and by pursuing sound fiscal policies. As a result, the CBA's credibility is reflected in the narrowing of interest rate differentials vis-à-vis the anchor currency, exchange rate and/or foreign reserves stability and either zero or low government debt. In sum, a credible CBA must be perceived as representing a durable and credible commitment to sound monetary and fiscal policies in order to deliver financial stability.

\subsection{Macau's CBA Experience}

Under the prevailing CBA, the Pataca is directly linked to the HKD, which is the anchor currency, and any Pataca issues must be fully backed by foreign exchange reserves. ${ }^{2}$ The current arrangement can be traced back to the year 1905 when the Banco Nacional Ultramarino (BNU) was granted the exclusive right to issue Pataca-denominated banknotes by Macau's government. The Pataca circulated for the first time on January 27, 1906 and has been Macau's legal tender ever since. However, in 1980, the Government transferred the exclusive right to issue Patacas from the BNU, which has traditionally acted as the government's banker, to the Issuing Institute of Macau (IEM), which regulated Macau's financial sector. ${ }^{3}$ Although, the BNU still continues to issue Pataca banknotes it does so as an agent bank of the IEM. In addition, the Macau Branch of the Bank of China (BOC) became the second noteissuing bank on October 16, 1995, following the government's renewal of its note issuance agreement with the BNU.

With the establishment of the Monetary and Foreign Exchange Authority of Macau (AMCM) on July 1, 1989, the authority to issue Patacas was transferred to then Portuguese-administered government. The Macau government still retains this function after the territory became a Chinese Special Administrative Region on December 20, 1999. ${ }^{4}$ The existing CBA requires that

\footnotetext{
${ }^{2}$ Macau's currency derives its name from a silver coin that used to circulate widely in Asia, the Mexican Eight Reales, which the Portuguese knew as the Pataca Mexicana.

${ }^{3}$ The Portuguese name for the IEM is Instituto Emissor de Macau.

${ }^{4}$ With the establishment of the Macau SAR, the Monetary and Foreign Exchange Authority of Macau simplified its name to the Monetary Authority of Macao and, in line with common practices, retained the acronym $A M C M$.
} 
the BNU or the BOC obtain non-interest bearing certificates of indebtedness (CI's) from the AMCM as legal backing for banknote issues. For this purpose, the two banks must deposit an equivalent amount of foreign exchange or interest earning assets, denominated in USDs or HKDs, with the AMCM. These foreign exchange deposits are counted as part of the official foreign AMCM-held exchange reserves and assure the full convertibility of the Macau Pataca with respect to its anchor currency at a fixed rate of MOP $1.03 /$ HKD. $^{5}$

The Pataca was originally pegged to the Portuguese Escudo (PTE) at a exchange rate of PTE 5.015/MOP. However, this historic relationship was abandoned on 9 April 1977 due to the Escudo's sharp devaluation, which occurred in the wake of Portugal's post-revolution economic turmoil. The Pataca was linked instead with the then floating HKD at a rate of MOP 1.075/HKD. In 1983, the Sino-British dispute over the future of Hong Kong sparked a confidence crisis in the territory that threatened to deteriorate into a full-blown economic crisis. In order to prevent this from happening, Hong Kong's government decided to readopt the currency board system on 17 October 1983, effectively linking the HKD to the USD at a rate of HKD 7.80/USD. As a result, the Pataca became indirectly pegged to the United States dollar at an exchange rate of about MOP 8.03/USD.

Macau's monetary policy is set within the broad framework stipulated by its Basic Law, which establishes long-term monetary stability as the AMCM's fundamental objective. Moreover, the AMCM's ability to defend the value of the Pataca is extremely high given the high level of international reserves in relation to imports and the virtual absence of sovereign external debt. In relation to fiscal policy, the fact that the Macau operates a currency board has served as a major incentive to follow a sound and prudent policies. As a result, Macau's government is debt free and has substantial fiscal reserves from accumulated budget surpluses in past years.

Macau's sound economic performance is acknowledged in financial markets, as evidenced by the recent upgrade in its international credit rating. After carefully assessing Macau's economic, social and political situation, Moody's Investor Service upgraded Macau's overall credit rating twice in

\footnotetext{
${ }^{5}$ At the end of 2002 , the foreign exchange reserves of the AMCM totalled $481 \%$ of the M1 and $31 \%$ of the M2 monetary aggregate.
} 
2003: once in February 2003, from Baa1 to A3, and again in October 2003, from A3 to A1. Nevertheless, the credibility of Macau CBA's has not been researched until now. In the next section we assess the credibility of the prevailing CBA by studying the effect of monetary and fiscal policies on the stochastic properties of EMP.

\section{Empirical Analysis}

The seminal contribution in the definition and measurement of EMP is that of Girton and Roper (hereafter, G-R)(1977), which uses the monetary approach to the balance of payments to measure the excess demand for a currency. ${ }^{6} \mathrm{In}$ their study, EMP is defined as the magnitude of money market disequilibrium that must be removed either through reserve or exchange rate changes. As such, G-R propose a summary statistic that is calculated as the sum of the change in foreign reserves (deflated by the level of the monetary base) and the change in the exchange rate, as a proxy measure of actual EMP. The rationale underlying their methodological approach is that exchange rate changes necessarily reflect a central bank's passive adjustment to EMP while purchases or sales of foreign assets are its active response.

Recall, however, that the Pataca is indirectly pegged to the USD, via the HKD. As a result, exchange rate changes cannot be used as an instrument by monetary authorities in Macau to affect EMP, which can only be removed by changes in foreign reserves. The first step in the assessing the credibility of Macau's CBA is, therefore, to determine whether or not changes in Macau's foreign reserves are a suitable measure of EMP. This assessment is undertaken next by applying the G-R model to foreign reserves data. In empirical terms, the G- $\mathrm{R}$ model is estimated using the following equation:

$$
r_{t}+e_{t}=\delta_{1} p_{t}^{*}+\delta_{2} y_{t}+\delta_{3} m_{t}+\delta_{4} d_{t}+\varepsilon_{t}
$$

where the dependent variable is the G-R summary statistic and $\varepsilon_{t}$ denotes the error term. The variables are defined as follows: $r_{t}$ is the change in foreign reserves (denominated in Patacas), $e_{t}$ is the exchange rate change, $p_{t}^{*}$ is the growth rate of foreign prices, $y_{t}$ is the change in domestic income, $m_{t}$ is the change in the money multiplier and $d_{t}$ the change in domestic credit. The

\footnotetext{
${ }^{6}$ For a brief literature review of EMP refer to Weymark (1998) and Spolander (1999).
} 
formal derivation of the model is presented in Appendix 1. Note that in the case of a fixed exchange regime exchange rate changes are zero by definition $\left(e_{t}=0\right)$ implying that the dependent variable in equation (1) is simply given by $r_{t}$.

The model's intuition is that, for given growth rates of foreign prices and domestic income, there will either be a proportionate loss in reserves with no change in the exchange rate, or a proportionate depreciation of the domestic currency with no change in reserves, or some combination of these two events whenever domestic credit increases and vice versa. Upon estimation, we find that G-R's model is fits the data quite well (refer to Appendix 1) which implies that EMP takes the form of reserve changes in the case of Macau's CBA. ${ }^{7}$ Having established this result, we address next the issue of CBA credibility by studying the stochastic properties of EMP. Specifically, we assess how EMP responds to changes in the explanatory variables that capture the effect of the CBA's three anchors, as discussed below.

\subsection{MSGARCH Model}

Following Gray (1996) and Braga de Macedo et al. (2003), our modelling approach combines a Markov regime-switching framework with an Exponential Generalized Autoregressive Conditional Heteroscedasticity (MSGARCH) model. We adopt a regime-switching methodology as it particularly well suited to deal with the dynamics of EMP, such as volatility clustering, asymmetric response to negative shocks, non-normality, time-varying transition probabilities and possible differences in the distributions across volatility states. The dependent variable of our two-regime MSGARCH model is EMP, defined as $\Delta s_{t}=100 \cdot \ln \left[R_{t} / R_{t-1}\right]$ where $R_{t}$ is the Pataca-denominated stock of foreign exchange reserves at time $t .^{8}$

Turning to the explanatory variables, the CBA's anchors of interest rate arbitrage, exchange rate arbitrage and fiscal discipline are respectively cap-

\footnotetext{
${ }^{7}$ Note, however, that G-R's model relies on some rather restrictive assumptions, such as purchasing power parity holding continuously, for example. This result should therefore always be interpreted within the context of the monetary model used to derive the G-R summary statistic.

${ }^{8}$ The measurement of reserve changes used here differs slightly from the one used in the estimation of the G-R model. In Appendix 1, we show how it is related the latter measure and also establish its validity as a EMP measure in the context of G-R (1977).
} 
tured using the following proxies: the change in Macau's interest rate differential vis-à-vis U.S. interest rates $\left(i^{*}\right)$, denoted by $I_{t}=\left(i_{t}-i_{t-1}\right)-\left(i_{t}^{*}-i_{t-1}^{*}\right) ;^{9}$ the percentage deviation of the MOP/USD exchange rate $\left(S_{t}\right)$ from its implied USD peg-value, defined as $D_{t-1}=100$. $\left[S_{t-1} / \operatorname{Peg}_{t-1}-1\right] ;{ }^{10}$ and, the change in Macau's current budget balance $\left(B B_{t}\right)$, which is measured as government's revenue less its expenditure and denoted by $B_{t}=100 \cdot\left(\frac{\Delta B B_{t}}{\left|\Delta B B_{t}\right|_{\max }}\right)$ where $\left|\Delta B B_{t}\right|_{\max }$ is the largest observed budget balance change expressed in absolute value terms.

The MSGARCH model allows for the possibility that the effects of anchors might differ across volatility states. The explanatory variables are therefore allowed to affect the mean, the conditional variance, and the time-varying state transition probabilities (TVTP) in each policy regime as follows:

$$
\begin{aligned}
\Delta s_{i t} & =\alpha_{i 0}+\alpha_{i 1} \Delta s_{t-1}+\alpha_{i 2} \Delta s_{t-2}+\alpha_{i I} I_{t-1}+\alpha_{i D} D_{t-1}+\alpha_{i B} B_{t-1}+e_{t} \\
\ln v_{i t} & =\beta_{i 0}+\beta_{i|e|}\left|\frac{e_{t-1}}{\sqrt{v_{t-1}}}\right|+\beta_{i e} \frac{e_{t-1}}{\sqrt{v_{t-1}}}+\beta_{i v} \ln v_{t-1}+\beta_{i I} I_{t-1}+\beta_{i D} D_{t-1}+\beta_{i B} B_{t-1} \\
\operatorname{Pr}\left(Z_{t}\right. & \left.=i \mid Z_{t-1}=i, \Psi_{t-1}\right)=\Phi\left(\gamma_{i 0}+\gamma_{i|I|}\left|I_{t-1}\right|+\gamma_{i|D|}\left|D_{t-1}\right|+\gamma_{i|B|}\left|B_{t-1}\right|\right) \\
e_{t} & =\sqrt{v_{i t}} \varepsilon_{t} \quad \varepsilon_{i t} \sim i . i . d t\left(d_{i}\right)
\end{aligned}
$$

where $\Phi(\cdot)$ is the standard normal cumulative distribution function and $t\left(d_{i}\right)$ denotes a standardised Student- $t$ distribution with $d_{i}$ degrees of freedom, a mean of zero and a unit variance. All explanatory variables are lagged one period in order to avoid the problem of contemporaneous simultaneity with the dependent variable.

The model's parameters will depend directly on each of the two possible values taken by the unobserved regime variable $Z_{t}$, denoted by the subscript $i=1,2$. We assume that $Z_{t}$ evolves according to a first-order Markov chain

\footnotetext{
${ }^{9}$ Upon estimation, however, we found that models estimated using the change in Macau's interest rate performed better on the basis of the AIC and SBC criteria. In addition, these models had no residual heteroscedasticity, as was the case with those that used the change in Macau's interest rate differential. As a result, subsequent estimations used $I_{t}=\left(i_{t}-i_{t-1}\right)$ as the proxy for interest rate arbitrage.

${ }^{10}$ Note that there is no MOP/USD market exchange rate as the AMCM simply sets this rate based on the 1.03 fixed rate via-à-vis the HKD and the HKD/USD market rate. The manner in which the MOP/USD exchange rate is set implies that exchange rate arbitrage opportunities automatically arise for the Pataca whenever the same happens to the HKD.
} 
where $\operatorname{Pr}\left(Z_{t}=i \mid Z_{t-1}=j, \Psi_{t-1}\right)$ is probability that the process is in regime $i$ at time $t$, conditional on it having being in regime $j$ during $t-1$, with $\Psi_{t-1}=\left\{Z_{t-1}, Z_{t-2, \ldots}, \Delta s_{t-1}, \Delta s_{t-2}, \ldots\right\}$ denoting the information set of period $t-1$. Although the regimes are not directly unobservable, it is nevertheless possible to infer the probability that the process is in regime $i$ at time $t$ by calculating $p_{i t}=\operatorname{Pr}\left(Z_{t}=i \mid \Psi_{t-1}\right)$. Let $t(\mu, v, d)$ denote a generic Student t-distribution with mean $\mu$, variance $\nu$ and $d$ degrees of freedom and whose density function is given by

$$
f(z)=\frac{\Gamma\left(\frac{d+1}{2}\right)}{\Gamma\left(\frac{d}{2}\right) \sqrt{\pi} \sqrt{d-2} \sqrt{\nu}}\left(1+\frac{(z-\mu)^{2}}{(d-2) \nu}\right)^{\frac{d+1}{2}}
$$

Under the assumptions made above, the dependent variable follows a mixture of two distributions each weighted with probability $p_{i t}$ for $i=1$, 2, i.e. $\Delta s_{i t} \mid \Psi_{t-1} \sim t\left(\mu_{i t}, v_{i t}, d_{i}\right)$ with $\mu_{i t} \equiv E\left[\Delta s_{i t} \mid \Psi_{t-1}\right]$ and where $v_{i t}$ is as defined above. The error term and the conditional volatility for period $t-1$ are then calculated as

$$
\begin{aligned}
& e_{t-1}=\Delta s_{t-1}-E\left(\Delta s_{t-1} \mid \Psi_{t-2}\right)=\Delta s_{t-1}-\sum_{i=1}^{2} p_{i t-1} \mu_{i t-1} \\
& v_{t-1}=\sum_{i=1}^{2} p_{i t-1}\left(\mu_{i t-1}^{2}+v_{i t-1}\right)-\left(\sum_{i=1}^{2} p_{i t-1} \mu_{i t-1}\right)^{2}
\end{aligned}
$$

In the mean equation, an effective interest rate arbitrage mechanism implies that $\alpha_{i I}>0$. For example, suppose that doubts about the economy's weakness lead to an outflow of capital. This causes the money supply to contract and domestic interest rates to rise relative to foreign interest rates $\left(I_{t-1}>0\right)$, thereby inducing an immediate counter-flow of funds so that reserves increase $\left(\Delta s_{t}>0\right)$. In the case of exchange rate arbitrage, if the AMCM-determined exchange rate weakens below (strengthens above) its implied MOP/USD peg-value, the ensuing selling (purchasing) pressure on foreign currency will ensure that the stock of foreign reserves decreases (increases), hence $\alpha_{i D}<0$ whenever $D_{t-1}>0$. Finally, one expects that an increase (decrease) in public savings $\left(B_{t-1}>0\right)$ be associated with an increase (decrease) in reserves $\left(\Delta s_{t}>0\right)$, ceteris paribus, which implies that $\alpha_{i B}>0$.

Turning to the conditional variance equation, the interest rate and exchange rate arbitrage mechanisms together with fiscal discipline are effective 
in reducing reserve volatility whenever $\beta_{i I}<0, \beta_{i D}<0$ and $\beta_{i B}<0$ respectively. In other words, a credible CBA should be extremely successful in responding to shocks by letting its automatic adjustment mechanisms work and by following sound fiscal policies. The effect of volatility clustering in the conditional variance equation is captured by the parameters $\beta_{|e|}$ and $\beta_{v}$. The latter parameter also captures the effect of persistence with $\beta_{v}<1$ implying that the conditional variance is stationary. The asymmetric response to shock is captured by the term $\beta_{e}$. Negative shocks increase conditional volatility more than would be the case with positive shocks whenever $\beta_{e}<0$. Finally, the parameters $\gamma_{i|I|}, \gamma_{i|D|}$ and $\gamma_{i|B|}$ respectively capture the effect of the three explanatory variables on the TVTP equations. While the signs of these parameters are not easily predictable a priori on theoretical grounds, the effect of the respective variable on the transition probability is easily understood upon estimation. For example, $\gamma_{i|I|}>0$ implies that (absolute) changes in interest rates increase the probability of the process remaining in regime $i$ at time $t$.

\subsection{MSGARCH Estimation Results}

The analysis is undertaken using monthly data for the period January 1990 until July 2003 but the effective sample only begins in April 1990. Hamilton's filter is used to construct the log-likelihood and the filtered probabilities for the whole sample. In order to better understand the effect of fiscal policy on EMP, we estimate two MSGARCH models: the first comprises all three anchors and is as specified above; the second, relies only on the interest rate and exchange rate arbitrage mechanisms and so excludes the term $B_{t-1}$ from all three equations. This approach allows us to infer the effect of the fiscal discipline variable by way of comparison with the model where this variable is not present. The two models are hereafter referred to as the full and the reduced model respectively.

The results of the full and reduced models are presented in Tables 1 and 2 respectively. Note that the $\mathrm{AIC}$ and $\mathrm{SBC}$ criteria select the full model as being the better model. Note that non-significant variables are excluded from an estimated equation whenever appropriate. Moreover, whenever a parameter did not significantly differ across regimes it was restricted to be the same. The estimated parameters of those explanatory variables that were not excluded from the models are all correctly signed and significantly different 
from zero at the $5 \%$ significance level in both cases. We label regime one as the low-volatility state and the high-volatility state as regime two. Both regimes have a first-order autoregressive element in the mean equation and we find no evidence of asymmetric responses to shocks. The $t$-distribution estimated degrees of freedom, which are rather low due to the likely presence of thick tails, do not differ much between regimes in both models. Not surprisingly, the null hypothesis of a normal distribution is also rejected.

Turning first to the reduced model's results, we find that the exchange rate arbitrage mechanism affects the mean in the low-volatility state as the parameter $\alpha_{1 D}(-0.7202)$ is correctly signed and significant at the $5 \%$ level. The fact that our analysis has detected this effect at all is particularly noteworthy, especially when one considers that the AMCM-determined MOP/USD exchange rate has deviated from its implicit peg-value by an average of less than one percent during the time period considered. It appears, however, that exchange rate arbitrage is clearly not as important as either interest rate arbitrage or fiscal discipline judging by magnitudes of the respective estimated parameter values.

We find evidence of the interest rate arbitrage effect being present in the mean equation across both regimes. However, this effect is much stronger in the high-volatility state as the estimated value of $\alpha_{2 I}$ (1.1512) is approximately twice as large as that of $\alpha_{1 I}$ (0.6926). Interest rate arbitrage is also effective in reducing volatility across both regimes but this time its effect it is more pronounced in the low-volatility state. We also find evidence of volatility clustering as the parameters $\beta_{1|e|}$ and $\beta_{2|e|}$ are significant, albeit at different significance levels. Unexpectedly, these parameters are signed differently across regimes. The estimates of $\beta_{1 v}$ and $\beta_{2 v}$ suggest moderate persistence in the high-volatility state and none in the other. Finally, there is no evidence of an indirect effect on volatility levels, via the TVTP, of either of these mechanisms. This last observation suggests that factors external to Macau might also important in accounting for regime change, especially those attributable to economic, social and political events in Hong Kong.

The results that emerge from the full model allow us to refine the insights obtained from the analysis of the reduced model. The inclusion of the fiscal discipline proxy seemingly obviates the need to include variables that capture volatility clustering and persistence effects. As before, none of the 
explanatory variables has an indirect effect on volatility and we find almost identical evidence for the effect of exchange rate arbitrage mechanism, which still only affects the mean of the low-volatility state $\left(\alpha_{1 D}=-0.7079\right)$. The major difference, however, lies in the manner in which the interest rate arbitrage mechanism now operates.

Although it has almost the same impact on the mean in both regimes as before, our analysis reveals that it affects the conditional variance differently across regimes. In particular, whilst interest rate arbitrage still reduces conditional variability in the high-volatility state $\left(\beta_{2 I}=-0.438\right)$, it is completely ineffective in doing so in the low-volatility state. Instead, our results indicate that fiscal discipline is solely responsible for reducing variability in this state $\left(\beta_{1 B}=-2.6763\right)$. Fiscal discipline also has a very strong impact on the mean in the low-volatility state. Indeed, it seems that fiscal discipline is far more important than the interest rate arbitrage mechanism in explaining changes in mean EMP upon comparison of the estimated values of $\alpha_{1 B}(2.0769)$ and $\alpha_{1 I}(0.6638)$.

This difference is glaringly obvious when we look at the smoothed probabilities of the high-volatility state of the two models (Figure 1). ${ }^{11}$ In the case of the reduced model, three distinct periods of high-volatility can be identified, namely 1990 until late 1992, mid 1993 until early 1995, and mid 1997 until late 1998. However, in the full model only the first and third periods are identifiable. The effect of fiscal discipline is striking in that it seems to reduce variability substantially in the intervening period. In effect, Macau's CBA has been in the low-volatility state since late 1992, with the brief exception of the relatively short period that began in October 1997. Note that this was precisely the month in which there was a strong speculative attack on the Hong Kong dollar following the contagion effect of the East Asian financial turmoil.

In order to gain a better insight into the CBA's dynamics, we plot separately in Figures 2 to 4 the EMP, interest rate and fiscal discipline time series together with the smoothed probability of the high-volatility regime (full model). We observe that the level and variability of EMP is much greater during the high-volatility period that runs from 1990 until late 1992

\footnotetext{
${ }^{11}$ The smoothed probabilities are the probabilities that EMP is in regime $i$ at time $t$ conditioned on the information of the whole sample.
} 
when compared to the remainder of the sample period (Figure 2). EMP's increased variability during this period mostly reflects global financial turbulence due to events such as the closure of BCCI (HK) in the summer of 1991, the Gulf War (August 1990) and the Exchange Rate Mechanism's crisis period (September 1992). However, we observe that the East Asian financial crisis period is not similarly accompanied by significant EMP variability, which is somewhat puzzling at first.

The most striking observation, however, relates to movements in Macau's interest rate during the East Asian crisis, which are relatively large (Figure 3). Given that EMP variability is not unusually high, as noted above, we infer that interest rate changes are bearing the brunt of the required adjustment thereby explaining the apparent puzzle. In other words, it appears that the interest rate arbitrage mechanism was allowed to operate unhindered throughout this period. As a result, Macau's interbank rates rose substantially and lead to considerable risk premiums vis-à-vis US interest rates, as is evident in Figure 5. Recall that one would expect to observe precisely such an interest rate premium in the face of exchange rate risk or persistent economic uncertainty in order to induce the desired counter-flow of capital. Finally, note that the change in government's fiscal stance has a low frequency over time, including during the East Asian crisis period (Figure 4). The low frequency undoubtedly reflects economic agent's perceptions regarding the credibility of Macau's fiscal policy and would appear to rationalise our finding that fiscal discipline contributes towards reduced EMP variability during periods of low-volatility.

\section{Conclusion}

A pure CBA signals its credibility by allowing the interest and exchange rate arbitrage mechanisms to function automatically and by pursuing sound fiscal policies. In order to study the credibility of Macau's CBA, we first establish that Macau's foreign reserve changes are a valid measure of EMP using Girton-Roper's (1977) monetary model. Next, we address the issue of credibility directly by studying the impact of monetary and fiscal policies on the stochastic properties of EMP using a MSGARCH model. Specifically, we assess how the dependent variable of EMP responds to lagged changes in explanatory variables that capture the three anchors of a pure CBA. 
Our results suggest that the exchange rate arbitrage mechanism operates effectively during periods of low-volatility but is clearly not as important as the other two anchors. More significantly, we establish that interest rate arbitrage affects the mean level of EMP in both regimes and contributes towards variability reduction in the high-volatility state. Fiscal discipline, on the other hand, is associated with variability reduction in the low-volatility state and is also more important than interest rate arbitrage in accounting for changes in mean EMP in this state. Fiscal fundamentals thus seem to have a more pronounced role in variability reduction in the low-volatility state whilst changes in Macau's interest rates, are more important in periods of high volatility. In other words, in "normal" times, Macau's sound fiscal stance is sufficient to ensure zero or low EMP, leaving interest rate arbitrage as the sole adjustment mechanism in periods of abnormal EMP.

Based on the above findings, we conclude that Macau's CBA is credible and has delivered financial stability. Indeed, the prevailing exchange rate arrangement has served as a major incentive for authorities to follow sound monetary and fiscal policies. In practice, the CBA's credibility is reflected in the low frequency of observed EMP, in the narrowing of Macau's interest rate differential vis-à-vis U.S. interest rates and in Macau's substantial fiscal reserves. Not surprisingly, Macau's sound economic performance has been increasingly acknowledged in international financial markets. 


\section{References}

Baliño, T. and C. Enoch (1997), "Currency Board Arrangements: Issues and Experiences", IMF Occasional Paper, No. 151.

Bennett, A. (1993) "The Operation of the Estonian Currency Board", IMF Staff Paper, Vol. 40, No. 2, pp. 451-470.

Braga de Macedo, J., Nunes, L. C. and L. Brites Pereira (2003) "Central Bank Intervention Under Target Zones: The Portuguese Escudo in the ERM", NOVA Working Paper, No. 435, September.

Connolly, M. and J. D. Silveira (1979) "Exchange Market Pressure in Postwar Brazil: An Application of the Girton-Roper Model", American Economic Review, Vol. 69, No. 3, pp. 448-454.

Girton, L. and D. Roper (1977) "A Monetary Model of Exchange Market Pressure Applied to the Postwar Canadian Experience", American Economic Review, Vol. 67, No. 4, pp. 537-548.

Gerlach, S. (2003) "Monetary Operations by Hong Kong's Currency Board", Manuscript, available at http://home.netvigator.com/ gerlach/Curr Board _Draft 3.pdf.

Gray, S. (1996) "Modeling the Conditional Distribution of Interest Rates as a Regime-Switching Process", Journal of Financial Economics, No.42, pp.27-62.

Hanke, S. H., Jonung, L. and K. Schuler (1993), Russian Currency and Finance, London: Routledge.

Hong Kong Monetary Authority (2000), "Hong Kong's Linked Exchange Rate System, Hong Kong: Hong Kong Monetary Authority", November, available at www.hkma.gov.hk.

Kim, I. (1985) "Exchange Market Pressure in Korea: An Application of the Girton-Roper Monetary Model", Journal of Money, Credit and Banking, Vol. 17, No. 2, pp. 258-263. 
Modeste, N.C. (1981) "Exchange Market Pressure during the 1970's in Argentina: An Application of the Girton-Roper Monetary Model", Journal of Money, Credit and Banking, Vol. 13, No. 2, pp. 234-240.

Officer, L. H. (1993), "Gold-Point Arbitrage and Uncovered Interest Arbitrage under the 1925-1931 Dollar-Sterling Gold Standard", Explorations in Economic History, Vol. 30, No. 1, pp. 98-127.

Pao, J.W. (2003), "The Currency Board Arrangement and the Macao Experience", Monetary Authority of Macau.

Scott, R. H. (1997), "Pegged Exchange Rate Systems in Macau and Hong Kong", Multinational Finance Journal, Vol. 1, No. 2, pp. 153-168.

Spolander, M. (1999) "Measuring Exchange Rate Pressure and Central Bank Intervention", Bank of Finland Studies, Series E, No. 17.

Thorton, J. (1995) "Exchange Market Pressure in Costa Rica, 1986-92: An Application of the Girton-Roper Model", International Economic Journal, Vol. 9, No. 1, pp. 67-72.

Tsang, S. (1999), "The Currency Board Arrangement in Hong Kong, China: Viability and Optimality Through the Crisis", Hong Kong Baptist University, Manuscript.

Weymark, D. N. (1998) "A General Approach to Measuring Exchange Market Pressure", Oxford Economic Papers, Vol. 50, pp. 106-121.

Wohar, M. E. and B. S. Lee (1992) "An Application of the Girton-Roper Monetary Model of Exchange Market Pressure: The Japanese Experience, 1959-1991", Rivista Internazionale di Science Economiche e Commerciali, Vol. 39, No. 12, pp. 993-1013 
Table 1: MSGARCH Estimation Results - Full Model

\begin{tabular}{|c|c|c|c|c|}
\hline Parameter & Estimate & Std Error & Est./Std. Error & p-value \\
\hline \multicolumn{5}{|c|}{ Mean Equation } \\
\hline$\alpha_{10}$ & 0.5699 & 0.2872 & 1.984 & $0.0236^{* *}$ \\
\hline$\alpha_{20}$ & - & - & - & - \\
\hline$\alpha_{11}$ & 0.1491 & 0.0677 & 2.203 & $0.0138^{* *}$ \\
\hline$\alpha_{21}$ & 0.4994 & 0.2144 & 2.329 & $0.0099^{* *}$ \\
\hline$\alpha_{1 D}$ & -0.7097 & 0.4298 & -1.651 & $0.0493 * *$ \\
\hline$\alpha_{2 D}$ & - & - & - & - \\
\hline$\alpha_{1 I}$ & 0.6638 & 0.211 & 3.146 & $0.0008^{* *}$ \\
\hline$\alpha_{2 I}$ & 1.1226 & 0.6599 & 1.701 & $0.0445^{* *}$ \\
\hline$\alpha_{1 B}$ & 2.0769 & 0.7058 & 2.943 & $0.0016^{* *}$ \\
\hline$\alpha_{2 B}$ & - & - & - & - \\
\hline \multicolumn{5}{|c|}{ Conditional Variance Equation } \\
\hline$\beta_{10}$ & 2.1254 & 1.289 & 1.649 & $0.0496^{\text {** }}$ \\
\hline$\beta_{20}$ & 3.1062 & 2.1475 & 1.446 & $0.074^{*}$ \\
\hline$\beta_{1 I}$ & - & - & - & - \\
\hline$\beta_{2 I}$ & -0.438 & 0.2248 & -1.948 & $0.0257^{* *}$ \\
\hline$\beta_{1 B}$ & -2.6763 & 1.0652 & -2.512 & $0.006^{* *}$ \\
\hline$\beta_{2 B}$ & - & - & - & - \\
\hline \multicolumn{5}{|c|}{ TVTP Equation } \\
\hline$\gamma_{10}$ & 3.0204 & 0.9996 & 3.022 & $0.0013^{* *}$ \\
\hline$\gamma_{20}$ & 0.9807 & 0.3927 & 2.498 & $0.0063^{* *}$ \\
\hline$d$ & 2.7201 & 1.384 & 1.965 & $0.0247^{* *}$ \\
\hline $\begin{array}{l}\text { Log-Likelihood } \\
\text { AIC } \\
\text { SBC } \\
\text { No. Obs. }\end{array}$ & $\begin{array}{c}-402.82 \\
-417.82 \\
-440.89 \\
160\end{array}$ & & & \\
\hline
\end{tabular}


Table 1 (continued): MSGARCH Estimation Results - Full Model

\begin{tabular}{|c|c|c|c|c|c|c|}
\hline \multirow[b]{3}{*}{ Lag } & \multicolumn{2}{|c|}{ Ljung-Box } & \multicolumn{2}{|c|}{ Ljung-Box } & \multicolumn{2}{|c|}{ ARCH-LM } \\
\hline & \multicolumn{2}{|c|}{ Standardised Residuals } & \multicolumn{2}{|c|}{ Squared Residuals } & \multicolumn{2}{|c|}{ Statistic } \\
\hline & $\mathbf{Q}$ & p-value & $\mathbf{Q}^{2}$ & p-value & $\mathbf{L M}$ & p-value \\
\hline Lag1 & 0.0136 & 0.9071 & 0.0645 & 0.7995 & 0.0629 & 0.8019 \\
\hline Lag2 & 1.0113 & 0.6031 & 0.1796 & 0.9141 & 0.1755 & 0.9160 \\
\hline Lag3 & 2.9064 & 0.4063 & 0.2473 & 0.9696 & 0.2445 & 0.9701 \\
\hline Lag4 & 2.9117 & 0.5727 & 0.2490 & 0.9929 & 0.2469 & 0.9930 \\
\hline Lag5 & 2.9118 & 0.7136 & 0.3811 & 0.9958 & 0.3796 & 0.9959 \\
\hline Lag6 & 4.1002 & 0.6631 & 0.4501 & 0.9984 & 0.4475 & 0.9984 \\
\hline Lag7 & 4.5825 & 0.7108 & 0.4670 & 0.9996 & 0.4695 & 0.9996 \\
\hline Lag8 & 5.1445 & 0.742 & 0.4874 & 0.9999 & 0.4962 & 0.9999 \\
\hline Lag9 & 5.6905 & 0.7704 & 0.5275 & 1.0000 & 0.5407 & 1.0000 \\
\hline Lag10 & 15.0001 & 0.1321 & 2.8595 & 0.9845 & 2.4718 & 0.9913 \\
\hline Lag11 & 15.1082 & 0.1776 & 2.9106 & 0.9919 & 2.5078 & 0.9958 \\
\hline Lag12 & 15.6868 & 0.206 & 2.9153 & 0.9961 & 2.4885 & 0.9982 \\
\hline Lag13 & 15.6898 & 0.2663 & 2.9282 & 0.9982 & 2.4759 & 0.9993 \\
\hline Lag14 & 15.9821 & 0.3145 & 3.0652 & 0.9990 & 2.5926 & 0.9996 \\
\hline $\operatorname{Lag} 15$ & 16.6134 & 0.3425 & 3.1500 & 0.9995 & 2.6378 & 0.9998 \\
\hline Lag16 & 17.4534 & 0.3569 & 3.2406 & 0.9997 & 2.6869 & 0.9999 \\
\hline $\operatorname{Lag} 17$ & 19.2465 & 0.3146 & 3.3026 & 0.9999 & 2.7140 & 1.0000 \\
\hline Lag18 & 20.6678 & 0.2965 & 3.3481 & 0.9999 & 2.7372 & 1.0000 \\
\hline Lag19 & 20.6679 & 0.3554 & 3.4019 & 1.0000 & 2.7580 & 1.0000 \\
\hline Lag20 & 20.9817 & 0.3982 & 3.4098 & 1.0000 & 2.8221 & 1.0000 \\
\hline
\end{tabular}

Notes: The parameter designations are as presented in the text. A double (single) asterisk denotes that the estimated parameter is significantly different from zero at the $5 \%(10 \%)$ level. 
Table 2: MSGARCH Estimation Results - Reduced Model

\begin{tabular}{|c|c|c|c|c|}
\hline Parameter & Estimate & Std Error & Est./Std. Error & p-value \\
\hline \multicolumn{5}{|c|}{ Mean Equation } \\
\hline$\alpha_{10}$ & 0.5901 & 0.1551 & 3.8040 & $0.0001^{* *}$ \\
\hline$\alpha_{20}$ & - & - & - & - \\
\hline$\alpha_{11}$ & 0.2007 & 0.0400 & 5.0220 & $0.0000^{* *}$ \\
\hline$\alpha_{21}$ & 0.4934 & 0.1406 & 3.5100 & $0.0002 * *$ \\
\hline$\alpha_{1 D}$ & -0.7202 & 0.2478 & -2.906 & $0.0018^{* *}$ \\
\hline$\alpha_{2 D}$ & - & - & - & - \\
\hline$\alpha_{1 I}$ & 0.6926 & 0.2394 & 2.8930 & $0.0019 * *$ \\
\hline$\alpha_{2 I}$ & 1.1512 & 0.3480 & 3.3080 & $0.0005^{* *}$ \\
\hline \multicolumn{5}{|c|}{ Conditional Variance Equation } \\
\hline$\beta_{10}$ & 1.6621 & 1.0408 & 1.5970 & $0.0551^{*}$ \\
\hline$\beta_{20}$ & 1.7900 & 1.2801 & 1.3980 & $0.0810^{*}$ \\
\hline$\beta_{1|e|}$ & -1.5750 & 1.0533 & -1.4950 & $0.0674 *$ \\
\hline$\beta_{2|e|}$ & 1.0532 & 0.6253 & 1.6840 & $0.0461^{* *}$ \\
\hline$\beta_{1 v}$ & 0.1969 & 0.1769 & 1.1130 & 0.1328 \\
\hline$\beta_{2 v}$ & 0.4927 & 0.2572 & 1.9160 & $0.0277^{* *}$ \\
\hline$\beta_{1 I}$ & -1.0812 & 0.4601 & -2.3500 & $0.0094 * *$ \\
\hline$\beta_{2 I}$ & -0.3170 & 0.1223 & -2.5930 & $0.0048^{* *}$ \\
\hline \multicolumn{5}{|c|}{ TVTP Equation } \\
\hline$\gamma_{10}$ & 2.8533 & 0.3844 & 7.4230 & $0.0000^{* *}$ \\
\hline$\gamma_{20}$ & 1.5148 & 0.3137 & 4.8280 & $0.0000^{* *}$ \\
\hline$d$ & 2.6351 & 0.4520 & 5.8300 & $0.0000^{* *}$ \\
\hline $\begin{array}{l}\text { Log-Likelihood } \\
\text { AIC } \\
\text { SBC } \\
\text { No. Obs. }\end{array}$ & $\begin{array}{c}-409.393 \\
-426.393 \\
-452.532 \\
160\end{array}$ & & & \\
\hline
\end{tabular}


Table 2 (continued): MSGARCH Estimation Results - Reduced Model

\begin{tabular}{|c|c|c|c|c|c|c|}
\hline \multirow[b]{3}{*}{ Lag } & \multicolumn{2}{|c|}{ Ljung-Box } & \multicolumn{2}{|c|}{ Ljung-Box } & \multicolumn{2}{|c|}{ ARCH-LM } \\
\hline & Standard & Residuals & Square & esiduals & & stic \\
\hline & $\mathbf{Q}$ & p-value & $\mathbf{Q}^{2}$ & p-value & $\mathbf{L M}$ & p-value \\
\hline Lag1 & 0.2191 & 0.6397 & 0.1791 & 0.6722 & 0.1764 & 0.6745 \\
\hline Lag2 & 0.3055 & 0.8583 & 0.2962 & 0.8624 & 0.2861 & 0.8667 \\
\hline Lag3 & 1.7360 & 0.6290 & 0.3504 & 0.9503 & 0.3401 & 0.9523 \\
\hline Lag4 & 1.9278 & 0.7490 & 0.3653 & 0.9852 & 0.3638 & 0.9853 \\
\hline Lag5 & 2.0818 & 0.8377 & 0.5333 & 0.9909 & 0.5402 & 0.9906 \\
\hline Lag6 & 2.5369 & 0.8643 & 0.6509 & 0.9955 & 0.6591 & 0.9953 \\
\hline Lag7 & 3.2735 & 0.8586 & 0.6620 & 0.9986 & 0.6746 & 0.9985 \\
\hline Lag8 & 3.6031 & 0.8910 & 0.6630 & 0.9996 & 0.6766 & 0.9996 \\
\hline Lag9 & 3.6364 & 0.9337 & 0.7693 & 0.9998 & 0.7903 & 0.9998 \\
\hline Lag10 & 7.6321 & 0.6647 & 1.8453 & 0.9974 & 1.6386 & 0.9984 \\
\hline Lag11 & 8.3408 & 0.6825 & 1.9579 & 0.9986 & 1.7780 & 0.9991 \\
\hline Lag12 & 8.4601 & 0.7482 & 1.9693 & 0.9995 & 1.7705 & 0.9997 \\
\hline Lag13 & 8.7973 & 0.7881 & 2.0991 & 0.9997 & 1.8750 & 0.9998 \\
\hline Lag14 & 9.5981 & 0.7909 & 2.2254 & 0.9998 & 1.9702 & 0.9999 \\
\hline Lag15 & 9.9065 & 0.8256 & 2.3313 & 0.9999 & 2.0258 & 1.0000 \\
\hline Lag16 & 10.7113 & 0.8269 & 2.3622 & 1.0000 & 2.0304 & 1.0000 \\
\hline Lag17 & 13.6416 & 0.6923 & 2.4389 & 1.0000 & 2.0693 & 1.0000 \\
\hline Lag18 & 16.6121 & 0.5499 & 2.4451 & 1.0000 & 2.0817 & 1.0000 \\
\hline Lag19 & 17.0464 & 0.5867 & 2.4467 & 1.0000 & 2.0519 & 1.0000 \\
\hline Lag20 & 18.1181 & 0.5796 & 2.5385 & 1.0000 & 2.0668 & 1.0000 \\
\hline
\end{tabular}

Notes: The parameter designations are as presented in the text. A double (single) asterisk denotes that the estimated parameter is significantly different from zero at the $5 \%(10 \%)$ level. 
Figure 1: (Smoothed) Probability of High Volatility State

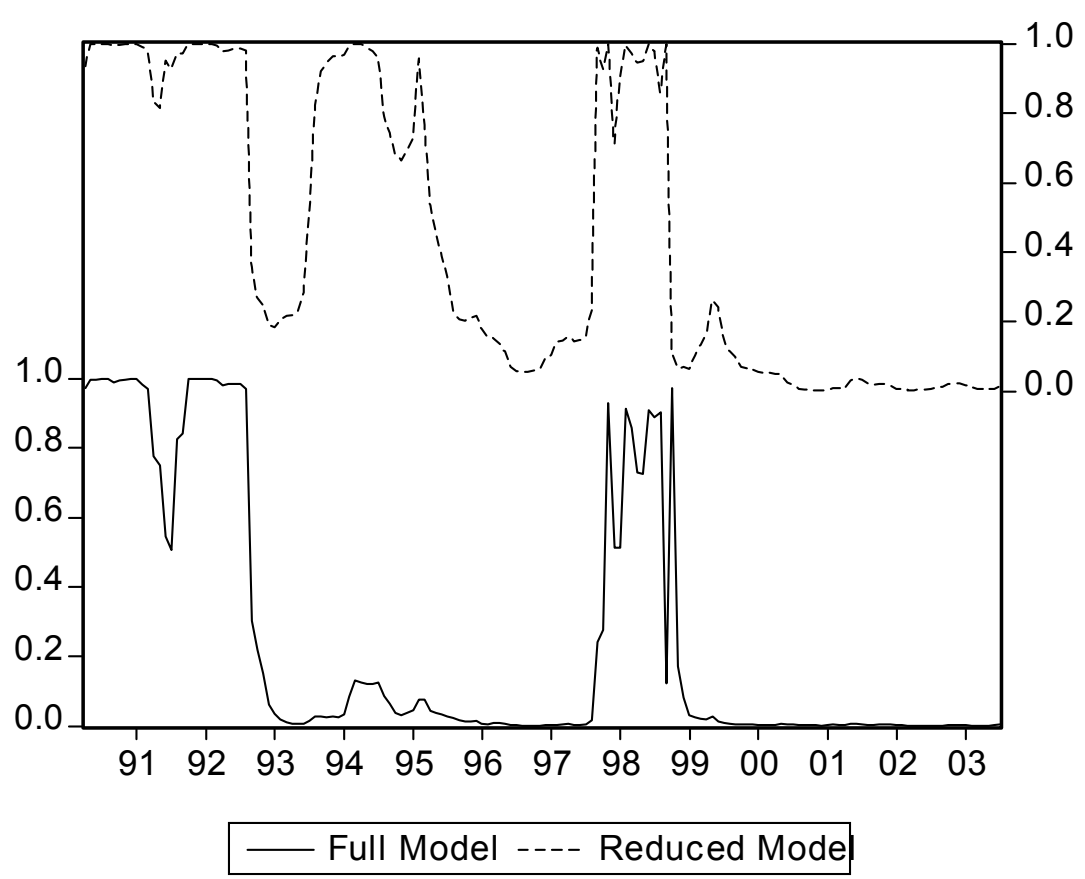

Figure 2: Reserve Changes \& Probability of High Volatility State

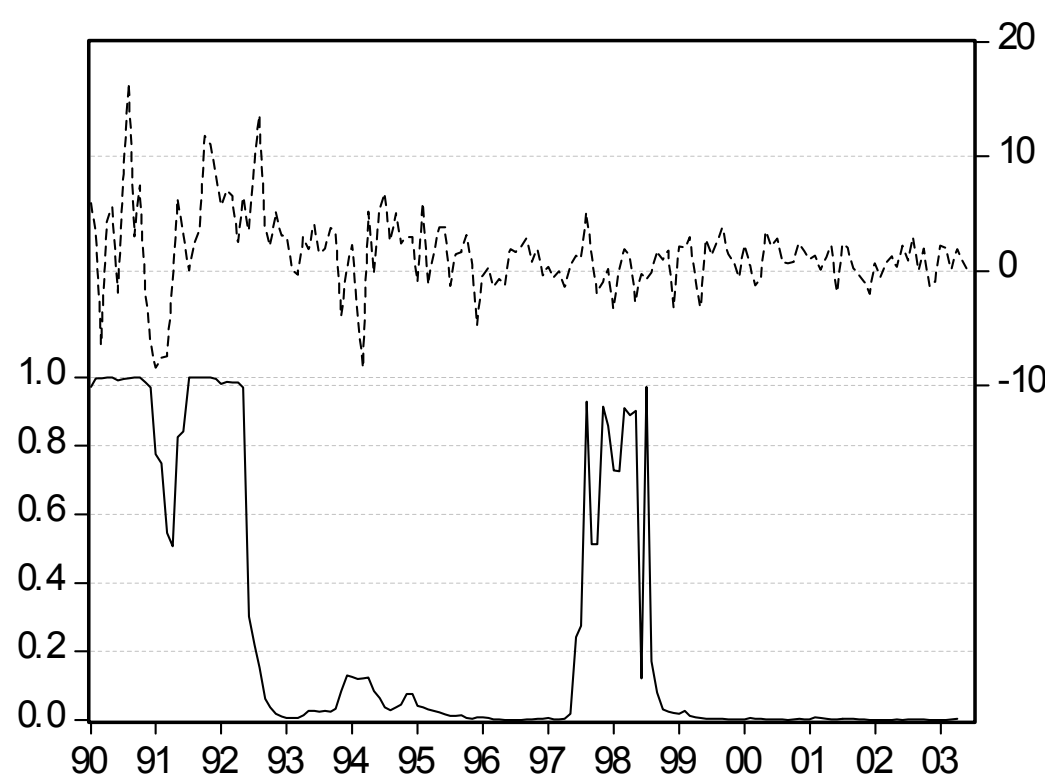

High Volatility Probability ---- Change in Reserves

23 
Figure 3: Interest Rate Change \& Probability of High Volatility State

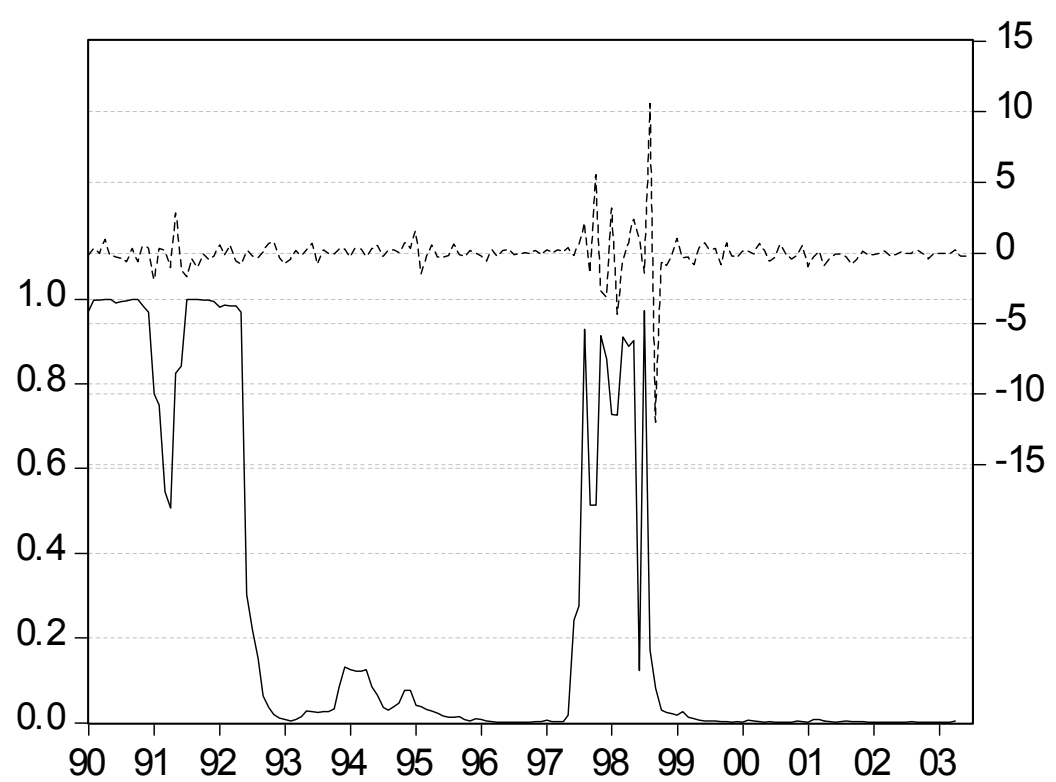

High Volatility Probability

Change In Interest Rate

Figure 4: Budget Balance \& Probability of High Volatility State

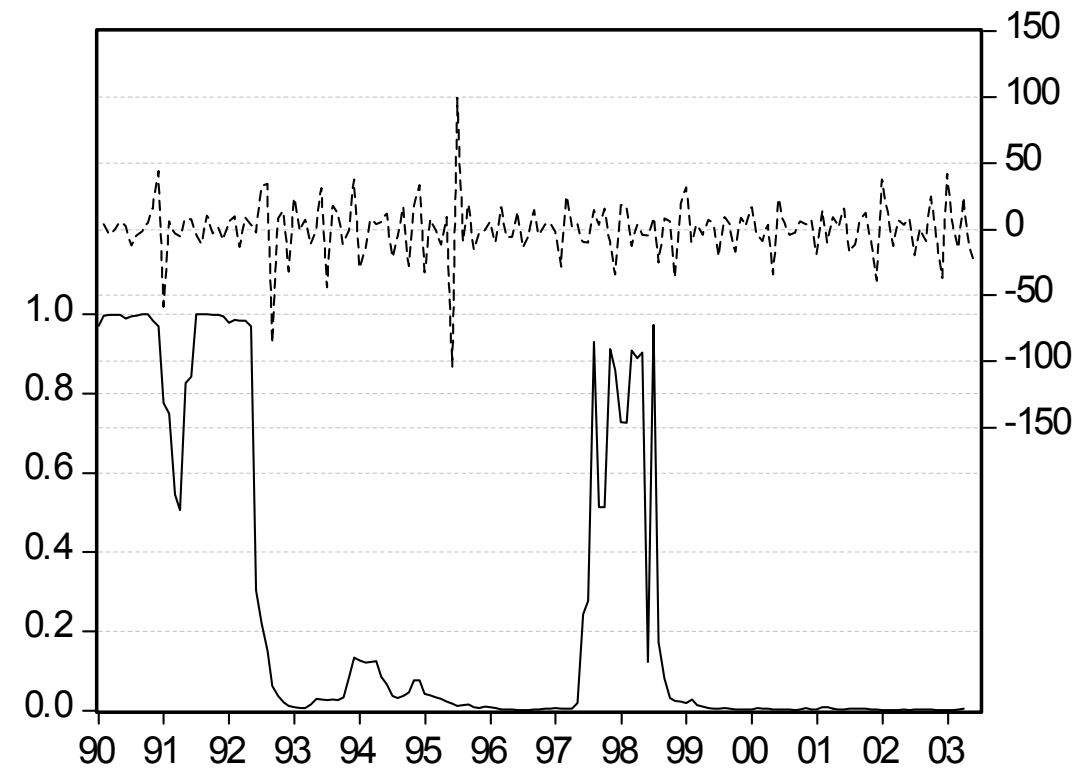

High Volatility Probability ---- Budget Balance 
Figure 5A: Macau, Hong-Kong \& US Interest Rates (monthly)

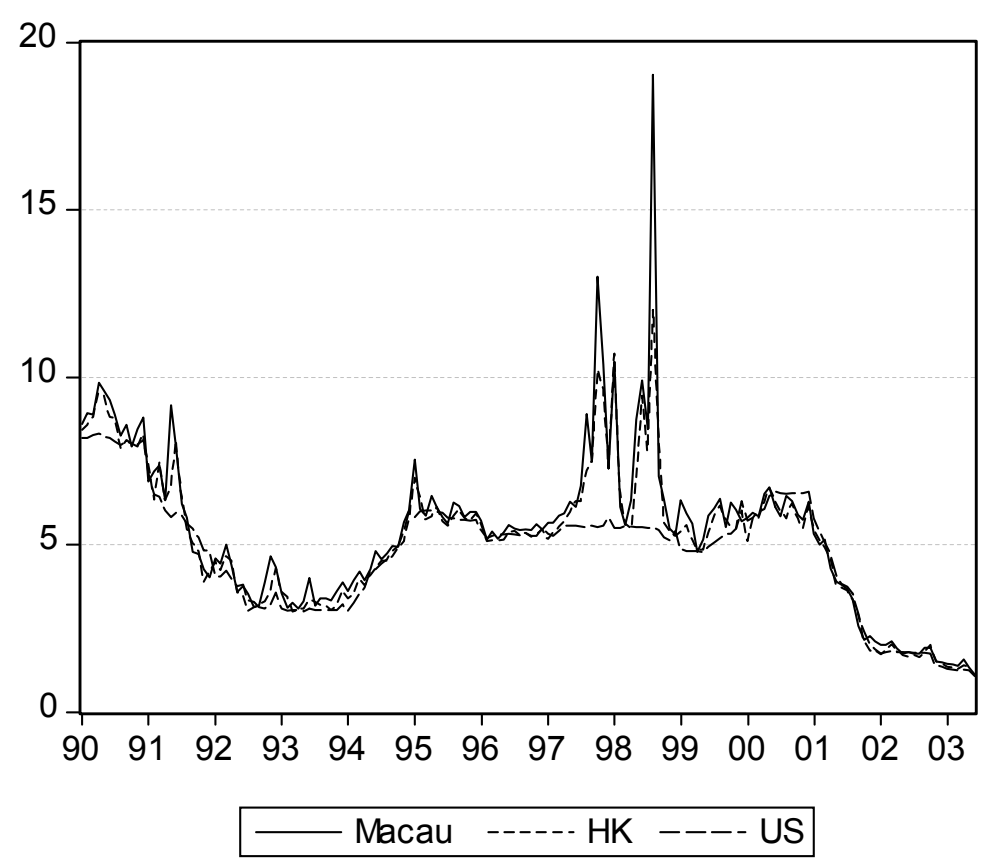

Figure 5B: Macau's Interest Rate Differential (monthly)

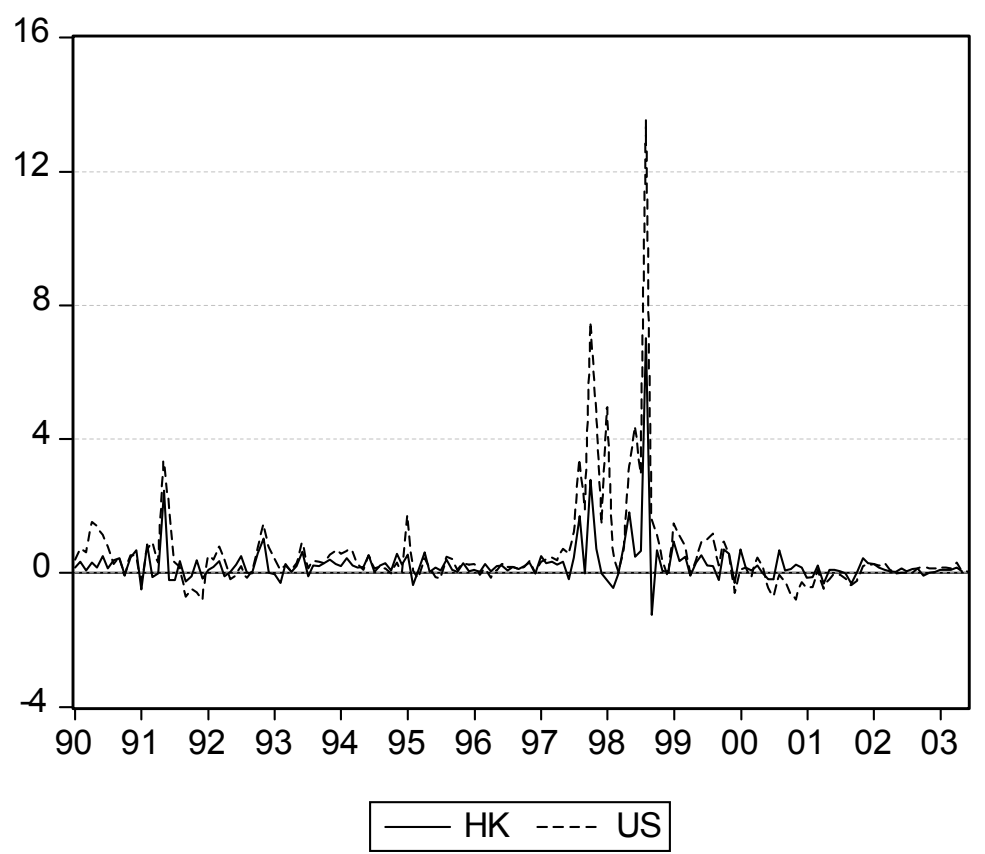




\section{Appendix 1: The Girton-Roper Model}

Girton and Roper (hereafter, G-R)(1977) define EMP as the magnitude of money market disequilibrium that must be removed either through reserve or exchange rate changes. ${ }^{12}$ As such, the sum of the rate of change in international reserves, deflated by the level of the monetary base, and the rate of change in the exchange rate itself, is taken to be a proxy measure of the actual amount of EMP. The main elements of G-R model are the demand for and the supply of money. The former is taken to be stable function of real income $\left(Y_{t}\right)$ and the domestic price level $\left(P_{t}\right)$, given by

$$
M_{t}^{d}=k P_{t} Y_{t}
$$

where $k$ denotes a constant. The supply of money is specified as the product of the money multiplier $\left(m_{t}\right)$ and the monetary base $\left(B_{t}=R_{t}+D C_{t}\right)$,where $R_{t}$ and $D C_{t}$ respectively denote net foreign asset holdings and domestic credit creation:

$$
M_{t}^{s}=m_{t} B_{t}
$$

The model assumes money-market equilibrium and also that the purchasing power parity relationship holds continuously, i.e.

$$
\begin{aligned}
M_{t}^{d} & =M_{t}^{s} \\
P_{t} & =\frac{P_{t}^{*}}{E_{t}}
\end{aligned}
$$

where $E_{t}$ is the nominal exchange rate, measured in units of foreign currency, and $P_{t}^{*}$ is the foreign price level. Substituting (A1.1) and (A1.2) into (1) and then taking the natural log yields

$$
\ln k+\ln P_{t}+\ln Y_{t}=\ln m_{t}+\ln B_{t}
$$

\footnotetext{
${ }^{12}$ An attractive feature of G-R's model is its broad applicability to intermediate exchange rate arrangements in which EMP is removed either through a combination of changes in the exchange rate or in foreign exchange rate reserves, or both. As examples, consider Connolly and Silveira (1979), Modeste (1981), Kim (1985), Wohar and Lee (1992), and Thorton (1995), who have applied the G-R model in the context of Brazil, Argentina, Korea, Japan and Costa Rica respectively.
} 
which can also be expressed as

$$
\ln k-\ln E_{t}+\ln P_{t}^{*}+\ln Y_{t}=\ln m_{t}+\ln \left(R_{t}+D C_{t}\right)
$$

after substituting the log version of equation (A1.4) into equation (A1.5) together with the definition of monetary base. Differentiating equation (A1.6) with respect to time yields ${ }^{13}$

$$
r_{t}+e_{t}=p_{t}^{*}+y_{t}-m_{t}-d_{t}
$$

where the lower case denotes changes in the log of the variables with the exception of $R_{t}$ and $D C_{t}$, respectively defined as $r_{t}=\frac{d R_{t} / d t}{R_{t}+D C_{t}}$ and $d_{t}=\frac{d D C_{t} / d t}{R_{t}+D C_{t}}$, i.e. the ratios of changes in reserves and of domestic credit changes with respect to the monetary base. The remaining variables are the growth rates of foreign prices $\left(p_{t}^{*}\right)$, of domestic income $\left(y_{t}\right)$ and of the money multiplier $\left(m_{t}\right)$. Under the model's assumptions, the parameters are restricted to take on the following values: $\delta_{1}=\delta_{2}=1$ while $\delta_{3}=\delta_{4}=-1$.

Note that in the case of fixed exchange regimes, exchange rate changes are zero by definition $\left(e_{t}=0\right)$, implying that $r_{t}$ is the sole dependent variable. This simplified variant of equation (A1.7) is estimated using the two-stage least squares (2SLS) method. The 2SLS methodology is chosen since it is highly likely that the dependent variable is correlated with the error term, thus rendering ordinary least squares (OLS) parameter estimates biased and inconsistent. Such a situation arises either because endogenously determined variables appear on the right-hand side of equation (A1.7) or because these are measured with error, or both. Lags of the model's variables are used as instruments in the 2SLS estimation process and all the regressors are stationary, as expected. Given the presence of serial correlation in the data, we also allow for the possibility that the errors follow an autoregressive (AR)

${ }^{13}$ The derivative of equation (6) w.r.t. time is

$$
\frac{d \ln P_{t}^{*}}{d t}-\frac{d \ln E_{t}}{d t}+\frac{d \ln Y_{t}}{d t}=\frac{d \ln m_{t}}{d t}+\frac{1}{R_{t}+D C_{t}} \frac{d R_{t}}{d t}+\frac{1}{R_{t}+D C_{t}} \frac{d D C_{t}}{d t}
$$

which can be rearranged as

$$
\frac{1}{R_{t}+D C_{t}} \frac{d R_{t}}{d t}+\frac{d \ln E_{t}}{d t}=\frac{d \ln P_{t}^{*}}{d t}+\frac{d \ln Y_{t}}{d t}-\frac{d \ln m_{t}}{d t}-\frac{1}{R_{t}+D C_{t}} \frac{d D C_{t}}{d t}
$$


or a moving average (MA) process of order $n$, where $n$ takes on the values 1 to 4 . In practice, the residuals are not serially correlated once the EMP equation had been amended to allow for an MA(2) process.

The G-R model applied to Macau uses monthly data for the sample period January 1990 until July 2003. In the model, the variables $R_{t}$ and $D C_{t}$ respectively denote Macau's net foreign asset holdings and domestic credit creation. The US consumer price index is used as a proxy of the foreign price level $P_{t}^{*}$ and the M1 money multiplier is chosen as it a better representative of the transactions behaviour of money. The choice of an appropriate measure of domestic income is rather more difficult since the usual measures of GDP or industrial production data are unavailable on a monthly basis for Macau. ${ }^{14}$

The parameter estimates of the model is presented in Table A1. We find that the estimates provide very strong evidence in support of the model as all estimated coefficients are correctly signed and significantly different from zero at the $5 \%$ significance level. In addition, the coefficient of the income level and of the money multiplier are close their hypothesised values $\left(\delta_{2}=1\right.$ and $\delta_{3}=-1$, respectively), as confirmed by the Wald tests. The diagnostic tests of the residuals indicate the absence of significant serial correlation, heteroscedasticity and non-normal behaviour. Overall, the model appears to fit the data quite well, as revealed by the plot of the actual versus the predicted data series Figure A1.

Finally, note also that reserve changes are measured as $\Delta s_{t}=100$. $\ln \left[R_{t} / R_{t-1}\right]$ in the case of the MSGARCH model, which is estimated in sec-

\footnotetext{
${ }^{14}$ On this score, we faced two practical options: the use of interpolation methods, which would convert annual GDP data into monthly GDP data, or the use of a suitable proxy. In unreported work, we evaluated monthly government expenditures as a potential proxy. We found that this proxy's behaviour over time compared well to that of actual GDP (annual) data once the monthly series had been converted into an annual one. Moreover, the use of the proxy in the G-R model yielded good results. In comparison, the interpolated GDP data performed poorly. The reason for this poor performance is possibly due to the fact that it is in general impossible to perfectly recover the high frequency series from the low frequency data. Since observing a series at a lower frequency provides fundamentally less information than observing the same series at a higher frequency, the results from the use of interpolation methods must be considered as suggestive rather than as providing the true values of the underlying series.
} 
tion $3 .{ }^{15}$ It can be easily shown that $\Delta s_{t}$ is also a suitable measure of EMP. To see this, first recall that equation (A1.7) can also be expressed as

$$
\frac{1}{R_{t}+D C_{t}} \frac{d R_{t}}{d t}=\frac{d \ln P_{t}^{*}}{d t}+\frac{d \ln Y_{t}}{d t}-\frac{d \ln m_{t}}{d t}-\frac{1}{R_{t}+D C_{t}} \frac{d D C_{t}}{d t}
$$

Note that $\frac{d \ln R_{t}}{d R_{t}}=\frac{1}{R_{t}}$, or equivalently $d R_{t}=R_{t} d \ln R_{t}$. Differentiating the latter expression with respect to time yields

$$
\begin{aligned}
\frac{d R_{t}}{d t} & =R_{t} \frac{d \ln R_{t}}{d t}+d \ln R_{t} \frac{d R_{t}}{d t} \\
& =\left(R_{t}+d R_{t}\right) \frac{d \ln R_{t}}{d t}
\end{aligned}
$$

which can be substituted into equation (A1.7') to obtain

$$
\frac{d \ln R_{t}}{d t}=\frac{R_{t}+D C_{t}}{R_{t}+d R_{t}}\left[\frac{d \ln P_{t}^{*}}{d t}+\frac{d \ln Y_{t}}{d t}-\frac{d \ln m_{t}}{d t}-\frac{1}{R_{t}+D C_{t}} \frac{d D C_{t}}{d t}\right]
$$

or equivalently,

$$
r_{t}=\theta\left[p_{t}^{*}+y_{t}-m_{t}-d_{t}\right]
$$

where $r_{t}$ now denotes the change in the $\log$ of $R_{t}$ and $\theta=\frac{R_{t}+D C_{t}}{R_{t}+d R_{t}}$. Note that in discrete time $(d t=1)$ we have $r_{t}=d \ln R_{t}=\ln \left[R_{t} / R_{t-1}\right]$, which is exactly the same change in reserves as $\Delta s_{t}$ (expressed on a scale of zero to one instead of as a percentage). The parameter estimates of the model given by equation (A1.8) are presented in Table A1. As before, we find that estimates provide very strong evidence in support of the model as all estimated coefficients are correctly signed and significantly different from zero. The coefficient of the income level and of the money multiplier are again close their hypothesised values and the diagnostic tests indicate the absence of significant serial correlation, heteroscedasticity and non-normal behaviour in the residuals.

\footnotetext{
${ }^{15}$ Without the loss of generality, we ignore the effect of scale in the exposition that follows and take the dependent variable to be given by $\Delta s_{t}=\ln \left[R_{t} / R_{t-1}\right]=d \ln R_{t}$.
} 
Table A1: GIRTON-ROPER Estimation Results

\begin{tabular}{|c|c|c|c|c|}
\hline $\begin{array}{c}\text { Parameter/ } \\
\text { Test }\end{array}$ & $\begin{array}{l}\text { Estimate/ } \\
\text { Statistic }\end{array}$ & Std. Error & $\begin{array}{c}\text { Est./Std. } \\
\text { Error }\end{array}$ & p-value \\
\hline \multicolumn{5}{|c|}{ Panel A: $r=d R_{t} /$ Base $_{t}$} \\
\hline$\delta_{1}$ & 0.6145 & 0.1043 & 5.8889 & $0.0000 * *$ \\
\hline$\delta_{2}$ & 0.7375 & 0.4409 & 1.6726 & $0.0964 *$ \\
\hline$\delta_{3}$ & -1.3549 & 0.6990 & -1.9385 & $0.0544^{* *}$ \\
\hline$\delta_{4}$ & -0.2969 & 0.1757 & -1.6900 & $0.0931 *$ \\
\hline Jarque-Bera & 6.1670 & - & - & $0.0458 * *$ \\
\hline$L M(3)$ & 0.2821 & - & - & 0.9634 \\
\hline$A R C H(3)$ & 5.3220 & - & - & 0.1497 \\
\hline $\operatorname{Wald}\left(H 0: \delta_{1}=1\right)$ & 13.6496 & - & - & $0.0003 * *$ \\
\hline Wald $\left(\mathrm{HO}: \delta_{2}=1\right)$ & 0.3546 & - & - & 0.5524 \\
\hline $\operatorname{Wald}\left(\mathrm{HO}: \delta_{3}=-1\right)$ & 0.2578 & - & - & 0.6124 \\
\hline $\operatorname{Wald}\left(\mathrm{HO}: \delta_{4}=-1\right)$ & 16.0193 & - & - & $0.0001 * *$ \\
\hline$R$-squared & -0.1132 & - & - & - \\
\hline Std Error Regression & 0.1982 & - & - & - \\
\hline Sum Squared Errors & 6.0104 & - & - & - \\
\hline Durbin-Watson & 1.9941 & - & - & - \\
\hline \multicolumn{5}{|c|}{ Panel B: $r=\ln \left(R_{t} / R_{t-1}\right)$} \\
\hline$\delta_{1}$ & 0.7287 & 0.1550 & 4.7002 & $0.0000 * *$ \\
\hline$\delta_{2}$ & 0.8253 & 0.4904 & 1.6827 & $0.0945^{*}$ \\
\hline$\delta_{3}$ & -1.3241 & 0.6897 & -1.9196 & $0.0538 * *$ \\
\hline$\delta_{4}$ & -0.4918 & 0.2352 & -2.0905 & $0.0382 * *$ \\
\hline Jarque-Bera & 0.6448 & - & - & 0.7243 \\
\hline$L M(3)$ & 4.6262 & - & - & 0.2013 \\
\hline$A R C H(3)$ & 1.6801 & - & - & 0.1736 \\
\hline Wald $\left(H 0: \delta_{1}=1\right)$ & 3.0607 & - & - & $0.0822 *$ \\
\hline $\operatorname{Wald}\left(\mathrm{HO}: \delta_{2}=1\right)$ & 0.1268 & - & - & 0.7221 \\
\hline Wald $\left(\mathrm{HO}: \delta_{3}=-1\right)$ & 0.2208 & - & - & 0.6390 \\
\hline $\operatorname{Wald}\left(\mathrm{HO}: \delta_{4}=-1\right)$ & 4.6646 & - & - & $0.0323 * *$ \\
\hline$R$-squared & -0.0970 & - & - & - \\
\hline Std Error Regression & 0.0408 & - & - & - \\
\hline Sum Squared Errors & 0.2537 & - & - & - \\
\hline Durbin-Watson & 1.9877 & - & - & - \\
\hline
\end{tabular}

Notes: The parameter designations are as presented in the text. $L M(t)$ and $A R C H(t)$ respectively denote the Breusch-Godfrey Serial Correlation LM and the ARCH-LM heteroscedasticity test statistics up to lag $t$ while Wald is the F-statistic of Wald parameter test under the null hypothesis (HO). The R-squared statistic is calculated as 1-(SSE/((N-1)SDV $\left.\left.{ }^{2}+\mathrm{N}^{*} \mathrm{MDV}^{2}\right)\right)$ where MDV and SDV are respectively the mean and standard deviation of the dependent variable. $\mathrm{N}=160$ is the number of observations. A double (single) asterisk indicates that the estimated parameter is significantly different from zero at the $5 \%(10 \%)$ level. 
Figure A1: Girton-Roper Model of EMP (monthly)

Changes in Foreign Reserves (Scaled by Monetary Base)

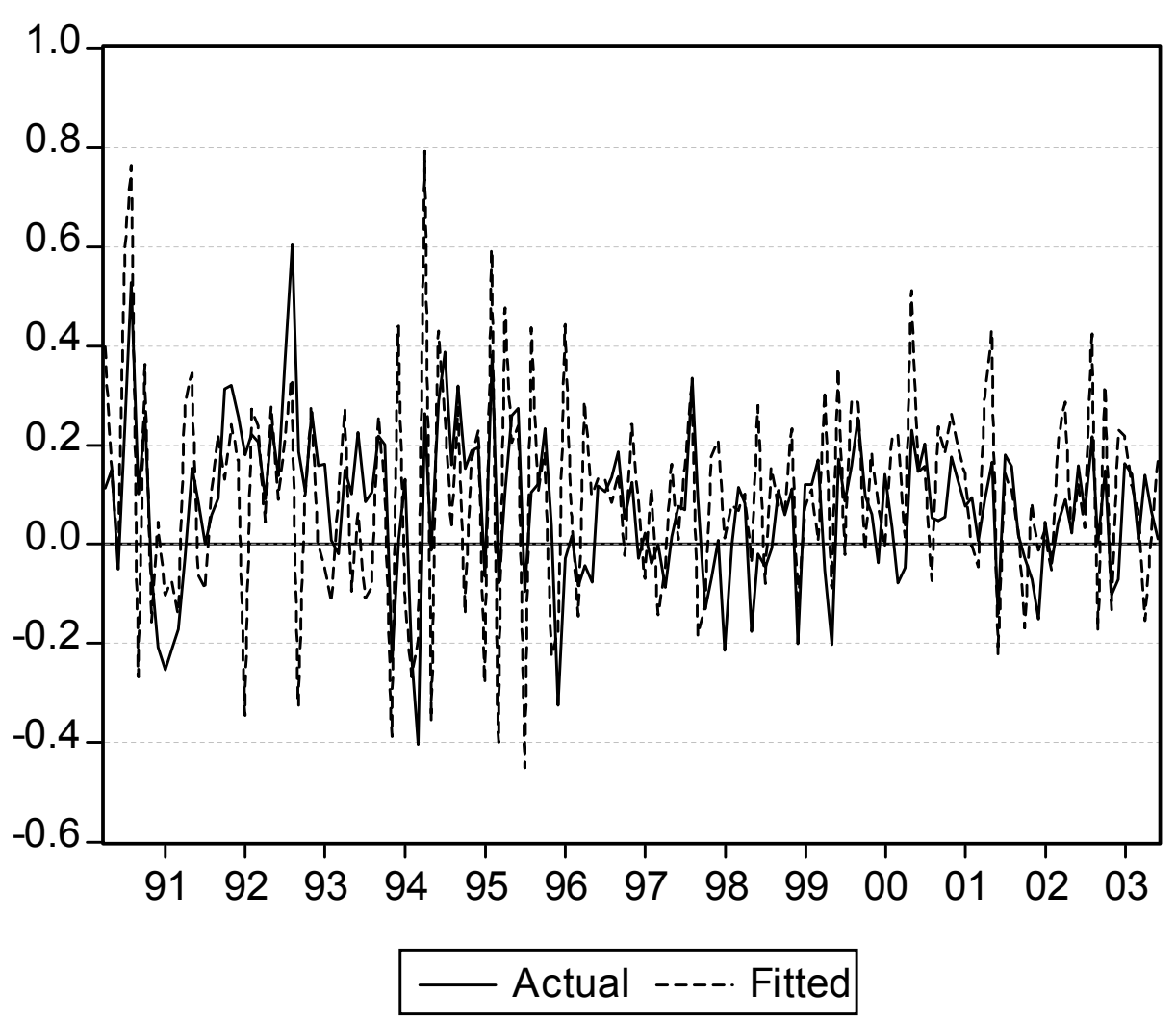




\section{Appendix 2. Descriptive Statistics of Foreign Reserve Changes}

In accordance with the model being estimated, we measure changes in reserves either as the ratio of reserve changes with respect to the monetary base $\left(B_{t}\right)$, denoted by $r_{t}=\frac{d R_{t} / d t}{B_{t}}$ or as $\Delta s_{t}=100 \cdot \ln \left[R_{t} / R_{t-1}\right]$. The descriptive statistics of these measures are given in Table A.2. The test statistics reveal that the distribution of reserve changes is skewed for both measures but with different signs. In the case of $r_{t}$, skewness is negative but close to zero while it is positive for $\Delta s_{t}$, indicating the presence of a long right tail. ${ }^{16}$ In both cases, the distribution is leptokurtic, i.e. it is more peaked and also has fatter tails when compared to the normal distribution, as revealed by the kurtosis test statistic. The formal test of normality, given by the Jarque-Bera statistic, clearly rejects the null hypothesis of reserve changes being normally distributed. The Ljung-Box $Q$-statistics detect the presence of significant serial autocorrelation and the ARCH-LM statistics suggest that the ARCH effects are significant. However, we note that the effects of the departure from normality, serial correlation and heteroscedasticity are more pronounced in the case of $\Delta s_{t}$. These stylised features are taken into account by our MSGARCH modelling framework when we study the stochastic properties of the changes in foreign reserves.

\footnotetext{
${ }^{16}$ Skewness is a measure of asymmetry around the mean of a series' distribution. The skewness of a symmetric distribution is zero (e.g. the normal distribution). Positive skewness means that a distribution has a long right tail while negative skewness implies that it has a long left tail. Kurtosis measures the peakedness or flatness of a series' distribution. The kurtosis of the normal distribution is three. A distribution is more peaked (leptokurtic) relative to the normal if the kurtosis is greater than three and it is flatter (platykurtic) if it is less than three.
} 
Table A2: Descriptive Statistics of Foreign Reserve Changes

\begin{tabular}{|c|c|c|c|c|}
\hline Variable & Statistic & Value & Null Hypothesis & p-value \\
\hline \multirow[t]{13}{*}{$r_{t}$} & Minimum & -0.404 & - & - \\
\hline & Maximum & 0.602 & - & - \\
\hline & Median & 0.090 & - & - \\
\hline & Mean & 0.075 & Mean $=0$ & 0.000 \\
\hline & Std Deviation & 0.152 & - & - \\
\hline & Skewness & -0.034 & - & - \\
\hline & Kurtosis & 4.040 & - & - \\
\hline & Jarque-Bera & 7.198 & Normality & 0.027 \\
\hline & $\rho(1)$ & 0.308 & - & - \\
\hline & $Q(1)$ & 15.337 & No Autocorrelation & 0.000 \\
\hline & $L M(1)$ & 3.702 & No ARCH & 0.045 \\
\hline & $\mathrm{ADF}$ & -3.834 & Unit Root & $-1.942 *$ \\
\hline & Phillips-Perron & -8.152 & Unit Root & $-1.942 *$ \\
\hline \multirow[t]{13}{*}{$\Delta s_{t}$} & Minimum & -8.448 & - & - \\
\hline & Maximum & 16.407 & - & - \\
\hline & Median & 1.446 & - & - \\
\hline & Mean & 1.519 & Mean $=0$ & 0.000 \\
\hline & Std Deviation & 3.509 & - & - \\
\hline & Skewness & 0.609 & - & - \\
\hline & Kurtosis & 6.221 & - & - \\
\hline & Jarque-Bera & 78.592 & Normality & 0.000 \\
\hline & $\rho(1)$ & 0.482 & - & - \\
\hline & $Q(1)$ & 37.672 & No Autocorrelation & 0.000 \\
\hline & $L M(1)$ & 22.163 & No ARCH & 0.000 \\
\hline & $\mathrm{ADF}$ & -19.490 & Unit Root & $-1.942 *$ \\
\hline & Phillips-Perron & -19.731 & Unit Root & $-1.942 *$ \\
\hline
\end{tabular}

Notes: The variable designations are as presented in the text. $\rho(1)$ is the value of the autocorrelation function and $Q(1)$ is the Ljung-Box Q-statistic at lag 1. $L M(1)$ denotes the ARCH-LM statistic for the squared standardised residuals at lag 1 . The fourth column gives the null hypotheses of the tests that were conducted. For example, the Jarque-Bera statistic tests for Normality while the ADF/Phillips-Perron procedures test for the presence of unit roots (no intercept or trend term). The last column contains the corresponding p-values, except for the case of the unit root tests where the number presented denotes the test's $5 \%$ critical value. 